\title{
Morpho-physiological Response of Gliricidia sepium to Seawater-induced Salt Stress
}

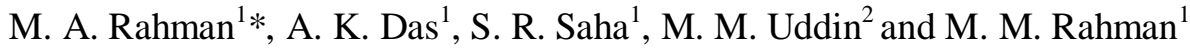 \\ ${ }^{1}$ Department of Agroforestry \& Environment, and ${ }^{2}$ Department of Crop Botany Bangabandhu Sheikh \\ Mujibur Rahman Agricultural University, Gazipur 1706, Bangladesh \\ *Corresponding author and Email: abiar@bsmrau.edu.bd
}

Received: 22 May 2019 Accepted: 09 November 2019

\begin{abstract}
Soil degradation due to the contamination of excessive saline water has been threatening soil health vis a vis plant productivity worldwide. Gliricidia sepium, a fertilizer tree, has come into limelight in recent decades in Bangladesh due to its potency in improving soil fertility. However, study on its suitability in coastal areas alongside identifying the salt-endurance limit is still lacking. Therefore, morphophysiological attributes of $G$. sepium under seawater-induced different levels of salt stress were analyzed in a pot experiment from March to May 2018 to gain an insight into its salt-adaptive mechanisms. Results revealed that seawater-induced salinity negatively affected the growth-related attributes, such as plant height, fresh weight of shoots, dry weights of shoots and roots, and leaf area. The reduction of growth was coincided with reductions in photosynthetic pigments and relative water content. Interestingly, salt tolerance index was not decreased in parallel with increasing dosages of seawater, indicating the salt tolerance capacity of $G$. sepium. Furthermore, enhanced accumulation of proline increased the osmoprotective capacity of $G$. sepium in order to overcome the salt-induced osmotic stress. The results of the present study concluded that G. sepium might be suitable for growing in the salt prone areas ranging $20-40 \mathrm{dSm}^{-1}$.
\end{abstract}

Keywords: Fertilizer tree, growth parameters, malondialdehyde, proline, photosynthetic pigments, soil salinity, salt tolerance index.

\section{Introduction}

Most of the parts of Bangladesh are more or less vulnerable to climatic menaces, but the coastal regions are predominantly very sensitive due to specific geo-climate and phylogenic activities. Bangladesh has a coastal area of 2.85 million ha, of which about 1.0 million ha along the coastal belt is under intimidation of different magnitudes of salinities (Rahman et al., 2016). Furthermore, sea-level rise provokes the salinity intrusion in the coastal plains causing demolition of the coastal ecosystems by degrading soil fertility, fresh water bodies and regeneration aptitude of mangroves (Rahman et al., 2017). High salinity causes multifarious co-operative events that adversely affect plant growth and development, and consequently yields, resulting in reduction of agricultural outputs by billions of dollars per annum (Song and Wang, 2014; Tahjib-Ul-Arif et al., 2018; Abdel Latef et al., 2019). Salt stress can trigger hyper-osmotic stress by reducing soil water availability and ion toxicity by accumulating excessive $\mathrm{Na}^{+}$in the cells, which 
severely impede common metabolic and physiological functions, leading to plant death in severe cases (Rajput et al., 2016; Acosta-Motos et al., 2017).

Apart from salinity problem, the organic matter content in Bangladesh soils is less than $1 \%$, ranging between 0.05 and $0.9 \%$ in most cases, which also restraints the agricultural productivity of Bangladesh (Biswas and Naher, 2019). Agriculture is intimately associated with food security and acts as a mainstay of Bangladesh's economy, which employs nearly half of the total population and contributes $14.23 \%$ to the gross domestic product (BER, 2019). The challenges to sustainable land and/ or agricultural management in Bangladesh are twofold. Firstly, to boost crop production and to maintain the soil quality of the agricultural lands, secondly is to the improvement of degraded land in an environmentally sustainable way (Karim et al., 2014). In this context, adoption of climate-smart organic agriculture, including crop residue recycling, legume plant inclusion in the cropping sequence or as intercrops, green leaf manuring and add-farmyard manure as supplementation or alternation of chemical fertilizers will be a propitious option to improve the soil health and crop productivity (Srinivasarao et al., 2011).

Gliricidia sepium (G. sepium), is a fast-growing medium sized $(10-15 \mathrm{~m})$ leguminous tree belonging to the family Fabaceae. It is one of the best-known multipurpose trees originated from Central America and Mexico, but has also widely spread to West Africa, West Indies, Southern Asia and tropical America (Solangi et al., 2010). It adapts very well in a wide range of soils ranging from eroded acidic $(\mathrm{pH}$ 4.5-6.2) soils, fertile sandy soils, heavy clay, calcareous limestone and alkaline soils (Wani et al., 2009). The tree is used for timber, firewood, hedges, medicinal purpose, charcoal, live fence, plantation shade, poles, soil stabilization, and even as mouse killer (Srinivasarao et al., 2011). However, G. sepium has come into limelight in recent decades to solve the soil fertility problem due to its capacity of improving organic matter content in the soil (Beedy et al., 2010; Makumba, 2003; Kwesiga et al., 2003). Furthermore, it also improves the water infiltration into the soil, increases water-holding capacity of the soil, reduces soil erosion, restores and improves soil quality, and ultimately increases the crop yields (Diouf et al., 2017). Growing Gliricidia plants on farm aile serves dual purpose as they produce green leaf manure that are rich in nitrogen $(\mathrm{N})$ and helps in conserving soil through reduced soil erosion (Rao et al., 2009). It is worth mentioning that application of $1 \mathrm{t} \mathrm{ha}^{-1}$ Gliricidia leaf manure provides $21 \mathrm{~kg} \mathrm{~N}, 2.5 \mathrm{~kg} \mathrm{P}, 18 \mathrm{~kg} \mathrm{~K}, 85 \mathrm{~g} \mathrm{Zn}$, $164 \mathrm{~g} \mathrm{Mn}, 365 \mathrm{~g} \mathrm{Cu}, 728 \mathrm{~g} F$ besides considerable quantities of $\mathrm{S}, \mathrm{Ca}, \mathrm{Mg}, \mathrm{B}$, Mo etc. (Srinivasarao et al., 2011). Farmers should therefore be encouraged to grow Gliricidia on a farm aile of fields for use in crop production, which is a sustainable means of maintaining soil fertility along with reducing the pressure on chemical fertilizers that are environmentally perilous.

Therefore, exploration of $G$. sepium towards calamitous areas in Bangladesh will be one of the auspicious options to serve the dual role, such as restoration of degraded soils and boost agricultural yield in an organic way. Unfortunately, being a new species in Bangladesh (Hossain et al., 1996), salinity tolerance limit alongside morpho-physiological response of $G$. sepium are not yet well understood. Therefore, the present study was aimed to determine the salt tolerance limits as well as appraise the effect of seawater induced salt stress on the morpho-physiological features of $G$. sepium plants.

\section{Materials and Methods}

\subsection{Study location, plant materials and growth conditions}

A pot experiment was conducted at the research field of the Department of Agroforestry and Environment, Bangabandhu Sheikh Mujibur Rahman Agricultural University, Bangladesh $\left(24^{\circ} 09^{`} \mathrm{~N}\right.$; $\left.90^{\circ} 26^{`} \mathrm{E}\right)$ for a period of 3 months 
(March to May 2018). The study site is $8.2 \mathrm{~m}$ above the sea level and characterized by a subtropical climate with hot summer and mild winter. The minimum and maximum temperatures of the research area were fluctuated between 17 to $23^{\circ} \mathrm{C}$ and 28 to $39^{\circ} \mathrm{C}$, respectively, during the experimental period. Healthy G. sepium seeds were surface-sterilized in $5 \%(\mathrm{v} / \mathrm{v})$ sodium hypochlorite solution containing $0.2 \%(\mathrm{v} / \mathrm{v})$ Tween-20 for $30 \mathrm{~min}$ followed by five times washed with distilled water $\left(\mathrm{dH}_{2} \mathrm{O}\right)$. Subsequently, the surfacesterilized seeds were incubated in $\mathrm{dH}_{2} \mathrm{O}$ at $26^{\circ} \mathrm{C}$ in the dark for $24 \mathrm{~h}$. The seeds were then transferred to small polythene bags containing $200 \mathrm{~g}$ of soils. Twenty-four days old G. sepium seedlings of uniform size were transplanted into each pot $(23 \mathrm{~cm}$ in height and $28 \mathrm{~cm}$ in diameter). The pots were previously filled with sandy loam soil mixture that was prepared by mixing oven-dried soil and cow dung at the ratio of 4:1 (in weight basis). However, the soils used was also treated with formaldehyde $(2.5 \mathrm{~mL}$ added in $100 \mathrm{~mL}$ of water) via spraying at the rate of 3.6-4.2 $\mathrm{L}$ of solution per $\mathrm{m}^{3}$ of soils to curtail the probability of developing soil-borne diseases. Subsequently, mix thoroughly and kept the soil covered for $24 \mathrm{~h}$. After removing odor of formaldehyde, the soils were used to fill the pots. In addition to cow dung, one liter of liquid fertilizer containing $1 \%$ of-urea, triple super phosphate and potassium sulphate was applied once to each pot on 20 days old-transplanted seedlings.

\subsection{Treatments composition}

After transplanting the seedlings into pots, the plants were irrigated with tap water for 6 days for adaptation before being exposed to seawaterinduced salt stress. Seawater collected from southern coastal area (Cox's Bazar sea beach) of Bangladesh (electrical conductivity of $69.6 \mathrm{dS} \mathrm{m}^{-}$ ${ }^{1}$, and $\mathrm{Na}^{+}, \mathrm{K}^{+}, \mathrm{Ca}^{2+}$ and $\mathrm{Mg}^{2+}$ concentrations of $578.70,20.38,19.90$ and $66.08 \mathrm{mmol} \mathrm{L}^{-1}$, respectively) was diluted with tap water to formulate different levels of salt treatments (20, 40 and $60 \mathrm{dS} \mathrm{m}^{-1}$ ) and the tap water was used as control treatment. For imposing salt stress, the uniformly grown plants were irrigated with the diluted seawater $(300 \mathrm{~mL})$ every day for a period of 90 days. The control plants were irrigated with tap water. Root and shoot samples were harvested at $90^{\text {th }}$ days of salt treatments for determining various morpho-physiological and biochemical parameters of G. sepium.

\subsection{Determination of growth parameters}

Plant height and leaf area were measured with a linear scale and following the equation of Carleton and Foote (1965), respectively. For determining biomasses of shoots and roots, plants were carefully uprooted at day 90th of salt stress imposition and washed with distilled water to remove adherent soil. Fresh weights (FWs) of shoots, dry weights (DWs) of shoots and roots were measured following the method described by Mostofa et al., (2015). Salt tolerance index (STI) was calculated following the formula of Rahman et al. (2017).

\subsection{Determination of leaf relative water content, chlorophyll contents}

The fresh, turgid and dry weights of the leaves were used to determine leaf relative water content (RWC) according to the formula described by Rahman et al., (2017). Chlorophyll (Chl) and carotenoids (Car) contents of freshly collected leaf samples were determined using $80 \%$ acetone as previously described by Misratia et al., (2013).

\subsection{Contents of proline}

The levels of proline (Pro) in shoots were determined following the methods described by Bates et al., (1973).

\subsection{Electrolyte leakage and lipid peroxidation}

Electrolyte leakage (EL) and the content of lipid peroxidation product [malondialdehyde (MDA)] in shoots were determined according to Lutts et al., (1996) and Tayebimeigooni et al., (2012), respectively.

\subsection{Statistical analysis}

The data were subjected to a one-way analysis of variance (ANOVA), following randomized block 
design and different letters indicate significant differences among treatments at $P<0.05$, according to least significant difference test (LSD) using Statistix 10 package. Data presented are means \pm standard errors (SEs) of three biological replications $(n=3)$ for each treatment.

\section{Results and Discussion}

\subsection{Effects of salinity on plant height, $F W$ of shoots, DW of shoots and roots, STI and leaf area of G. sepium}

Salinity had considerable negative effects on plant height. This stress caused a significant reduction of plant height by $16.63,25.94$ and $35.26 \%$ at day $90^{\text {th }}$ upon exposure of plants to 20 , 40 and $60 \mathrm{dS} \mathrm{m}^{-1}$ salinity levels, respectively, as compared to the respective control values in $G$. sepium (Table 1). Similarly, shoot FWs was significantly attenuated by 46.74, 65.48 and $77.77 \%$ upon exposure of $90^{\text {th }}$ day salt treatments at the level of 20,40 and $60 \mathrm{dS} \mathrm{m}^{-1}$ salinity levels, respectively, as compared to the respective control values (Table 1). Nevertheless, the negative consequences of salinity on growth performance of G. sepium were assessed by determining DW of shoots and roots. DW of salt-stressed shoots reduced by $30.72,45.10$ and $47.71 \%$, whereas, root DW by $41.92,65.38$ and $73.08 \%$ at 20,40 and $60 \mathrm{dS} \mathrm{m}^{-1}$ salinity levels, respectively, compared to that of control. STI, a reliable criterion for salt tolerance (Abbas et al., 2013), was also differentially affected by salt stress. STI decreased by $46.87 \%$ at the highest dosage of $60 \mathrm{dS} \mathrm{m}^{-1}$ seawater and STI obtained 66.83 and $50.55 \%$ at 20 and $40 \mathrm{dS}$ $\mathrm{m}^{-1}$, respectively (Table 1). Leaf area is the most sensitive growth parameter in response to salt stress (Qados, 2011). Reduction of leaf area progressively augmented with increasing salinity levels, and leaf area was found to reduce by $49.01,51.49$ and $57.55 \%$ at day $90^{\text {th }}$ in comparison to control upon application of 20, 40 and $60 \mathrm{dS} \mathrm{m}^{-1}$ salinity levels to plants, respectively (Table 1). The attenuation of growth-related parameters under high salinity clearly manifested that salt stress interferes various physiological and metabolic processes of plant upon which growth relies on (Table 1). In general, plant growth is intricately connected to meristem activity, cell division and expansion, carbon fixation, as well as uptake of water and nutrients (Pan et al., 2016; Rahman et al., 2016; Rahman et al., 2018). All of these processes are rigorously affected by high salinity, resulting in reduced growth performance of plants, which is further supported by the findings of Rahman et al., (2018) in Achras sapota plant. However, the reduced leaf area observed in the salt-exposed plants (Table 1) might help in minimizing the water loss by transpiration, which in turn can favor the retention of toxic ions in the roots and limiting the translocation of these ions to the aerial parts of the plant (Theerawitaya et al., 2015; Rangani et al., 2016; Rahman et al., 2018).

Table 1. Effects of salinity on plant height, shoot fresh weight (FW), shoot and root-dry weight (DW), salt tolerance index (STI) and leaf area in G. sepium plants after 90 days exposure

\begin{tabular}{|c|c|c|c|c|c|c|}
\hline Trea & $\begin{array}{l}\text { Plant height } \\
(\mathrm{cm})\end{array}$ & $\begin{array}{c}\text { Shoot FW } \\
(\mathrm{g})\end{array}$ & $\begin{array}{c}\text { Shoot DW } \\
(\mathrm{g})\end{array}$ & $\begin{array}{c}\text { Root DW } \\
(\mathrm{g})\end{array}$ & STI & $\begin{array}{r}\text { Leaf : } \\
\text { plan } \\
\end{array}$ \\
\hline $\mathrm{Co}$ & $150.33 \pm 8.83^{\mathrm{a}}$ & $103.13 \pm 1.45^{\mathrm{a}}$ & $12.75 \pm 0.14^{\mathrm{a}}$ & $3.47 \pm 0.35^{\mathrm{a}}$ & . & 1618.7 \\
\hline 20 & $.76^{\mathrm{b}}$ & & & $2.01 \pm 0.01^{\mathrm{b}}$ & & 825 \\
\hline $40 c$ & $\pm 2.03^{b c}$ & $35.6 \pm 1.41^{\mathrm{c}}$ & $7.00 \pm 0.14^{\mathrm{c}}$ & $1.20 \pm 0.23^{\mathrm{bc}}$ & $50.57+0$ & 785.20 \\
\hline $60 \mathrm{dS} / \mathrm{m}$ & $97.33 \pm 4.06^{\mathrm{c}}$ & $22.93 \pm 1.97^{\mathrm{d}}$ & $6.67 \pm 0.44^{\mathrm{c}}$ & $0.93 \pm 0.13^{\mathrm{c}}$ & $46.87+2.68^{b}$ & $687.20 \pm 11.02^{\mathrm{c}}$ \\
\hline
\end{tabular}

Values are means \pm standard errors of three biological replications $(n=3)$. Different superscripted letters within a column indicate statistically significant differences among the treatments according to a least significant difference test $(P<0.05)$. FW, fresh weight; DW, dry weight; STI, salt tolerance index. 

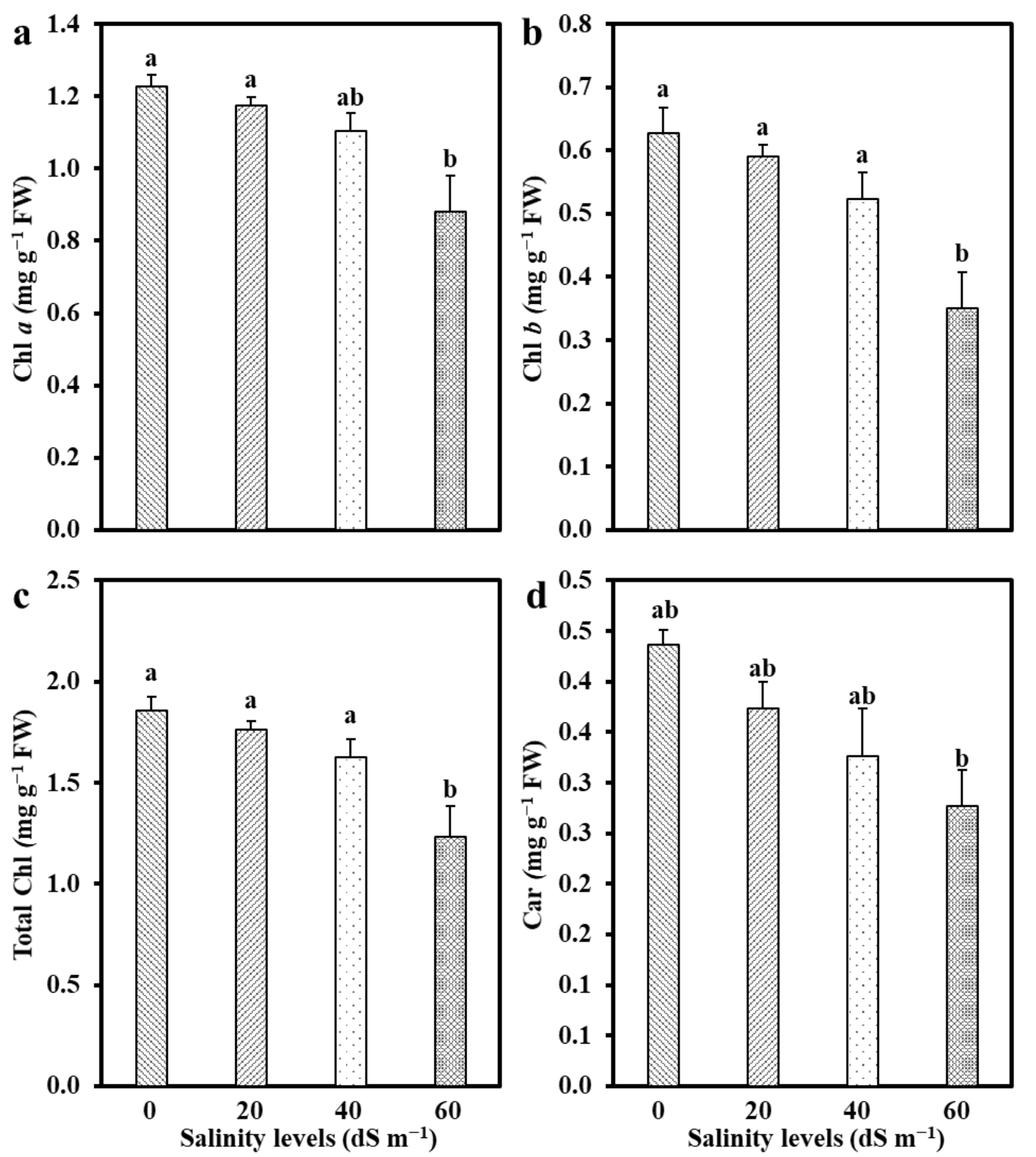

Figure 1. Effects of salinity $\left(0,20,40\right.$ and $60 \mathrm{dS} \mathrm{m}^{-1}$ ) on (a) Chl $a$, (b) Chl $b$, (c) Chl (a+b) (d) Car content of Gliricidia sepium after 90 days exposure. Bars represent standard errors of the means $(n=3)$. Different letters indicate significant differences among the treatments at $P<$ 0.05, according to a least significant difference test. Chl, Chlorophyll; Car, Carotenoid; FW, fresh weight. 

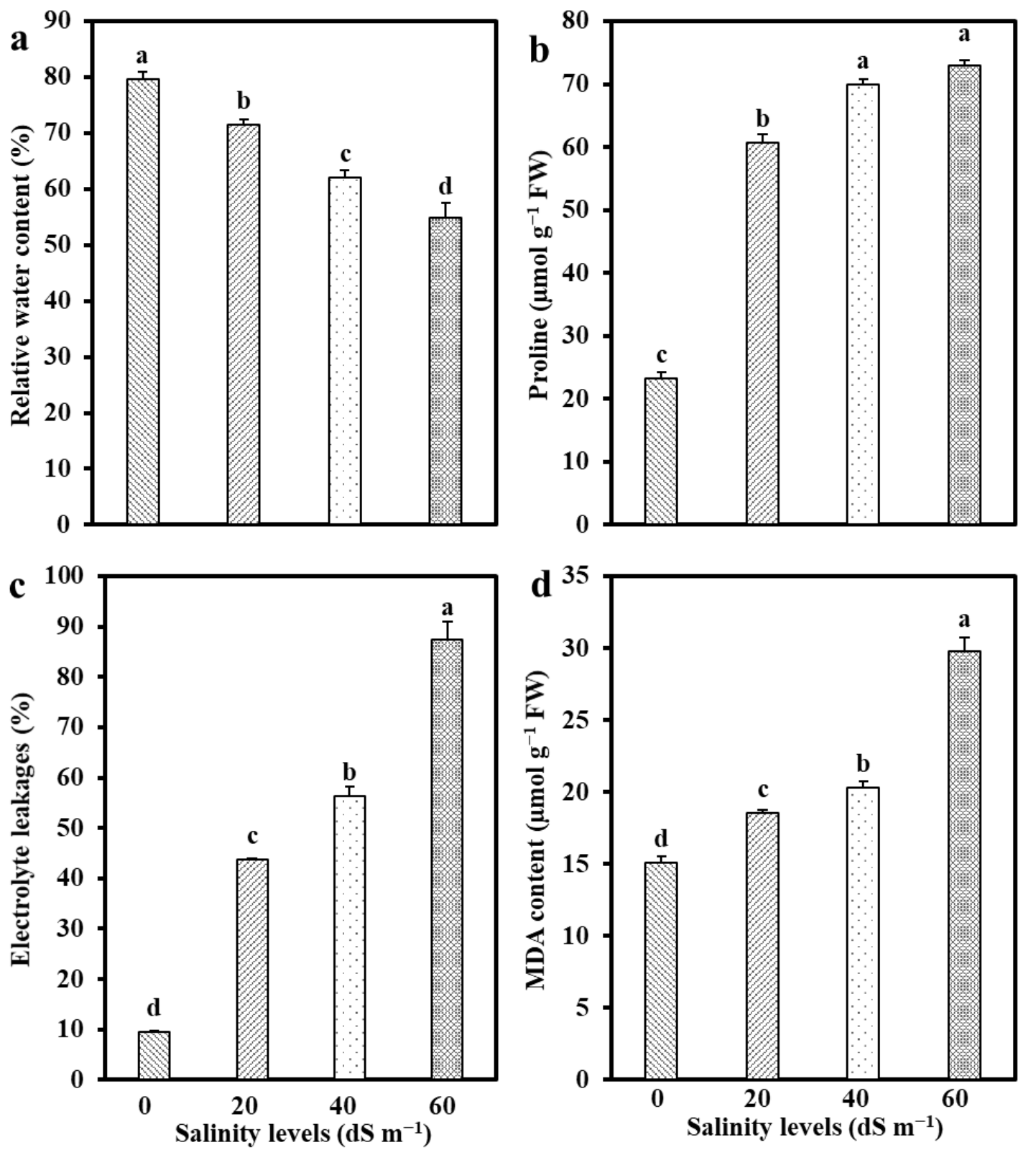

Figure 2. Effects of salinity on (a) relative water content, (b) proline, (c) electrolyte leakage (d) malondialdehyde (MDA) content of Gliricidia sepium after 90 days exposure $(0,20,40$ and $\left.60 \mathrm{dS} \mathrm{m}^{-1}\right)$. Bars represent standard errors of the means $(n=3)$. Different letters indicate significant differences among the treatments at $P<0.05$, according to a least significant difference test. FW, fresh weight. 


\subsection{Effects of salinity on photosynthetic pigment}

Irrigation of $G$. sepium plants with diluted seawater caused gradual and significant decreases in the contents of $\mathrm{Chl} a$ (by 4.35, 10.06 and $28.26 \%$ at day $90^{\text {th }}$ ), Chl $b$ (by $5.86,16.50$ and $44.15 \%$ at day $90^{\text {th }}$ ), total Chls (by 5.21, 12.39 and $33.75 \%$ at day $90^{\text {th }}$ ) and carotenoid content (by $14.52,25.19$ and $36.64 \%$ at day $90^{\text {th }}$ ) upon imposition of 20, 40 and $60 \mathrm{dS} \mathrm{m}^{-1}$ salinity, respectively, compared with plants irrigated with tap water (Fig. 1). Photosynthetic efficiency of a plant determines the overall performance, which is emulated by growth and biomass parameters. In the current study, the levels of Chl $a$ and $b$, as well as total Chls, were progressively declined with the rise of salinity level and exposure time, indicating that the photosynthetic performance of G. sepium was hampered, which contributed to the decrease in plant biomass (Fig. 1; Table 1).

The reduction in Chl levels and consequent biomass loss were evident in other studies under salt stress, and the possible cause was attributed to the direct effects of accumulated $\mathrm{Na}^{+}$and ROS (Qin et al., 2010; Mostofa et al., 2015). Chl $a$ is the most abundant and integral part of the lightharvesting complex, whereas $\mathrm{Chl} b$ as an accessory pigment acts indirectly in photosynthesis by transmitting photons to the Chl $a$ (Chen, 2014; Gururani et al., 2015). Thus, a higher level of Chl $a$ than Chl $b$ at all concentrations of seawater (Fig. 1a, b) might have contributed to the improved efficiency of G. sepium in resisting salt-induced loss of photosynthetic capacity (Table 1), as was reported in Atriplex helimus by Bendaly et al., (2016) and in Acacia auriculiformis plant by Rahman et al., (2017). Besides functioning as accessory pigments, carotenoids are known to be involved in protecting photosynthetic reaction center from chlorophyll-mediated generation of singlet oxygen $\left({ }^{1} \mathrm{O}_{2}\right)$ by quenching triplet states of Chls, and thus stabilizing and protecting the lipid phase of thylakoid membrane (Gururani et al., 2015).

\subsection{Effects of salinity on leaf $R W C$, content of Pro, leaf EL, and MDA of G. sepium}

In response to seawater-induced salinity, leaf RWC decreased by $10.10,21.98$ and $31.16 \%$ at day $90^{\text {th }}$ under 20,40 and $60 \mathrm{dS} \mathrm{m}^{-1}$ salinity levels, respectively, compared to control (Fig. 2a). To understand the mechanisms associated with osmotic adjustment under salt stress, we have determined the level of Pro in G. sepium plants under normal and salt stress conditions. Pro content remarkably increased by 161.99 , 201.95 and $214.91 \%$ at day $90^{\text {th }}$ upon imposition of 20,40 and $60 \mathrm{dS} \mathrm{m}^{-1}$ diluted seawater, respectively, compared to control (Fig. 2b). To assess the cell membrane integrity under salt stress, we determined the level of EL in the shoots of G. sepium (Fig. 2c). At day $90^{\text {th }}$ of salt imposition, EL content significantly increased by 361.43 and $495.96 \%$ at 20 and $40 \mathrm{dS} \mathrm{m}^{-1}$ salinity levels, respectively, relative to control. Nevertheless, the increment of EL levels showed the maximum $823.73 \%$ at the highest salinity dose $\left(60 \mathrm{dS} \mathrm{m}^{-1}\right)$ than that of untreated respective control. To assess the cell membrane integrity under salt stress, we determined the levels of lipid peroxidation product MDA in the shoots of G. sepium MDA content significantly increased by $22.83,34.82$ and $97.50 \%$ at day $90^{\text {th }}$ upon imposition of 20,40 and $60 \mathrm{dS} \mathrm{m} \mathrm{m}^{-1}$ salinity, respectively, compared to control plants (Fig. $2 \mathrm{~d})$. In the present study, reduction of leaf RWC in salt-stressed plants upon exposure to salinity indicating the salt-mediated induction of physiological water deficit in G. sepium (Fig. 2a). However, enhanced accumulation of Pro in salt-stressed plants might help adjust to water deficit conditions (Fig. 2b). Pro is known to provide improved protection against salinity by scavenging free radicals, stabilizing membranes, proteins and enzymes, and maintaining ion homeostasis (Kishor and Sreenivasulu, 2014). Nonetheless, higher accumulation of toxic ions under salt stress lead to the generation of reactive oxygen species (ROS). ROS predominantly attacks the membrane, causing lipid peroxidation that leads to the generation of MDA and loss of essential electrolytes (Penella et al., 2016). The levels of MDA content and EL in G. sepium 
plants enhanced to a lower extent at low and moderate salinity levels (20-40 dS m${ }^{-1}$ ), where it was sharply increased at high dosage of salinity $\left(60 \mathrm{dS} \mathrm{m}^{-1}\right)$, which indicate that G. sepium plants could resist themselves from salt-induced membrane damage up to a certain level of salinity.

\section{Conclusions}

Our findings concluded that exposure of $G$. sepium plants to seawater-induced salinity adversely affects the performance of the whole plant, particularly by inhibiting growth and development. Nevertheless, the adapted stress tolerance mechanisms of $G$. sepium at a salinity range of $20-40 \mathrm{dsm}^{-1}$ could be attributed to (1) maintained higher dry biomass, (2) maintained optimum water status in terms of elevated RWC, (3) abundance of primary photosynthetic pigment Chl $a$ over accessory pigment $\mathrm{Chl} b$ to sustain favourable photosynthetic rate, and (4) accumulation of osmolyte like Pro to maintain osmoprotectant capacity under salt-stress. Nevertheless, we postulated that established plants of this species might be tolerant to salt stress higher than the level used in this study because seedlings are more sensitive to high soluble salt levels than established plants.

\section{Acknowledgements}

This study was funded by National Science and Technology (NST). We also thank all faculty members and staffs of Department of Agroforestry and Environment, Bangabandhu Sheikh Mujibur Rahman Agricultural University, Bangladesh. All authors read and approved the final manuscript.

\section{References}

Abbas MK., Ali AS., Hasan HH., Ghal RH. 2013. Salt tolerance study of six cultivars of rice (Oryza sativa L.) during germination and early seedling growth. Journal of Agricultural Science, 5:250259.
Abdel Latef, AAH., Mostofa MG., Rahman MM., Abdel-Farid IB., Tran LSP. 2019. Extracts from yeast and carrot roots enhance maize performance under seawater-induced salt stress by altering physio-biochemical characteristics of stressed plants. Journal of Plant Growth Regulation, 1-14.

Acosta-Motos JR., Ortuño MF., Bernal-Vicente A., Diaz-Vivancos P., Sanchez-Blanco MJ., Hernandez JA. 2017. Plant responses to salt stress: adaptive mechanisms. Agronomy, 7: 18.

Bates LS., Waldren RP., Teare ID. 1973. Rapid determination of free proline for waterstress studies. Plant and Soil, 39(1):205207.

Beedy TL., Snapp SS., Akinnifesi FK., Sileshi GW. 2010. Impact of Gliricidia sepium intercropping on soil organic matter fractions in a maize-based cropping system. Agriculture, Ecosystems and Environment, 138(3-4):139-146.

Bendaly A., Messedi D., Smaoui A., Ksouri R., Bouchereau A., Abdelly C. 2016. Physiological and leaf metabolome changes in the xerohalophyte species Atriplex halimus induced by salinity. Plant Physiology and Biochemistry, 103:208-218.

Bangladesh Economic Review (BER). 2019. Ministry of Finance, Government of Bagladesh.

Biswas JC., Naher UA. 2019. Soil nutrient stress and rice production in Bangladesh. In Advances in Rice Research for Abiotic Stress Tolerance, Woodhead Publishing, 431-445 pp.

Carleton AE., Foote WH. 1965. A comparison of methods for estimating total leaf area of barley plants 1. Crop Science, 5(6):602603.

Chen M. 2014. Chlorophyll modifications and their spectral extension in oxygenic 
photosynthesis. Annual Review of Biochemistry, 83:317-340.

Diouf A., Ndiaye M., Fall-Ndiaye MA., Diop TA. 2017. Maize crop N uptake from organic material of Gliricidia sepium coinoculated with rhizobium and Arbuscular mycorrhizal fungus in SubSaharian Africa sandy soil. American Journal of Plant Sciences, 8(3):428.

Gururani MA., Venkatesh J., Tran LSP. 2015. Regulation of photosynthesis during abiotic stress-induced photoinhibition. Molecular Plant, 8(9):1304-1320.

Hossain MK., Islam SA., Islam QN., Tarafdar MA., Zashimuddin M. 1996. Growth and biomass productions of the international provenance trial of Gliricidia sepium in Bangladesh. Chittagong University Studies, Science, 20(1):77-82.

Karim Z., Qureshi BA., Mumtaz M., Qureshi S. 2014. Heavy metal content in urban soils as an indicator of anthropogenic and natural influences on landscape of Karachi-a multivariate spatio-temporal analysis. Ecological Indicators, 42:20-31.

Kishor PBK., Sreenivasulu N. 2014. Is proline accumulation per se correlated with stress tolerance or is proline homeostasis a more critical issue?. Plant, Cell and Environment, 37(2):300-311.

Kwesiga F., Akinnifesi FK., Mafongoya PL., McDermott MH., Agumya A. 2003. Agroforestry research and development in southern Africa during the 1990s: review and challenges ahead. Agroforestry Systems, 59(3):173-186.

Lutts S., Kinet JM., Bouharmont J. 1996. NaClinduced senescence in leaves of rice (Oryza sativa L.) cultivars differing in salinity resistance. Annals of Botany, 78(3):389-398.

Makumba W. 2003. Nitrogen use efficiency and carbon sequestration in legume tree-based agroforestry systems. A case study in

\begin{abstract}
Malawi. PhD Thesis, Wagenigen University and Research Centre, Wagenigen, The Netherlands.
\end{abstract}

Misratia KM., Ismail MR., Hakim MA., Musa MH., Puteh A. 2013. Effect of salinity and alleviating role of gibberellic acid (GA3) for improving the morphological, physiological and yield traits of rice varieties. Australian Journal of Crop Science, 7(11):1682.

Mostofa MG., Saegusa D., Fujita M., Tran LSP. 2015. Hydrogen sulfide regulates salt tolerance in rice by maintaining $\mathrm{Na}^{+} / \mathrm{K}^{+}$ balance, mineral homeostasis and oxidative metabolism under excessive salt stress. Frontiers in Plant Science, 6:1055.

Pan YQ., Guo H., Wang SM., Zhao B., Zhang JL., Ma Q., Yin HJ., Bao AK. 2016. The photosynthesis, $\mathrm{Na}^{+} / \mathrm{K}^{+}$homeostasis and osmotic adjustment of Atriplex canescens in response to salinity. Frontiers in Plant Science, 7:848.

Penella C., Landi M., Guidi L., Nebauer SG., Pellegrini E., San Bautista A., Remorini D., Nali C., López-Galarza S., Calatayud A. 2016. Salt-tolerant rootstock increases yield of pepper under salinity through maintenance of photosynthetic performance and sinks strength. Journal of Plant Physiology, 193:1-11.

Qados AMA. 2011. Effect of salt stress on plant growth and metabolism of bean plant Vicia faba (L.). Journal of the Saudi Society of Agricultural Sciences, 10(1):715.

Qin J., Dong WY., He KN., Yu Y., Tan GD., Han L., Dong M., Zhang YY., Zhang D., Li AZ., Wang ZL. 2010. NaCl salinityinduced changes in water status, ion contents and photosynthetic properties of Shepherdia argentea (Pursh) Nutt. seedlings. Plant, Soil and Environment, 56(7):325-332. 
Rahman MM., Haque MA., Nihad SAI., Howlader MRA., Akand MMH. 2016. Morpho-physiological response of Acacia auriculiformis as influenced by seawater induced salinity stress. Forest Systems, 25(3):071.

Rahman MM., Mostofa MG., Rahman MA., Miah MG., Saha SR., Karim MA., Tran LSP. 2018. Insight into salt tolerance mechanisms of the halophyte Achras sapota: an important fruit tree for agriculture in coastal areas. Protoplasma, 256(1):181-191. doi.org/10.1007/s00709-018-1289-y.

Rahman MM., Rahman MA., Miah MG., Saha SR., Karim MA., Mostofa MG. 2017. Mechanistic Insight into salt tolerance of Acacia auriculiformis: the importance of ion selectivity, osmoprotection, tissue tolerance, and $\mathrm{Na}^{+}$exclusion. Frontiers in Plant Science, 8:155.

Rajput VD., Minkina T., Yaning C., Sushkova S., Chapligin VA., Mandzhieva S. 2016. A review on salinity adaptation mechanism and characteristics of Populus euphratica, a boon for arid ecosystems. Acta Ecológica Sinica, 36(6):497-503.

Rangani J., Parida AK., Panda A., Kumari A. 2016. Coordinated changes in antioxidative enzymes protect the photosynthetic machinery from salinity induced oxidative damage and confer salt tolerance in an extreme halophyte Salvadora persica L. Frontiers in Plant Science, 7: 50.

Rao CS., Wani SP., Sahrawat KL., Rajasekharao B. 2009. Nutrient management strategies in participatory watersheds in semi-arid tropical India. Indian Journal of Fertilisers, 5(12):113-128.

Solangi AH., Mal B., Kazmi AR., Iqbal MZ. 2010. Preliminary studies on the major characteristic, agronomic feature and nutrient value of Gliricidia sepium in coconut plantations of Pakistan. Pakistan Journal of Botany, 42(2):825-832.

Song J., Wang B. 2014. Using euhalophytes to understand salt tolerance and to develop saline agriculture: Suaeda salsa as a promising model. Annals of Botany, 115(3):541-553.

Srinivasarao C., Venkateswarlu B., Dinesh Babu M., Wani SP., Dixit S., Sahrawat KL., Sumanta K. 2011. Soil health improvement with Gliricidia green leaf manuring in rainfed agriculture, on farm experiences. Central Research Institute for Dryland Agriculture, Santoshnagar, PO Saidabad, Hyderabad.

Tahjib-Ul-Arif M., Siddiqui MN., Sohag AAM., Sakil MA., Rahman MM., Polash MAS., Mostofa MG., Tran LSP. 2018. Salicylic acid-mediated enhancement of photosynthesis attributes and antioxidant capacity contributes to yield improvement of maize plants under salt stress. Journal of Plant Growth Regulation, 37(4):13181330.

Tayebimeigooni A., Awang Y., Mahmood M., Selamat A., Wahab Z. 2012. Leaf water status, proline content, lipid peroxidation and accumulation of hydrogen peroxide in salinized Chinese kale (Brassica alboglabra). Journal of Food, Agriculture and Environment, 10:371-374.

Theerawitaya C., Tisarum R., Samphumphuang T., Singh HP., Cha-Um S., Kirdmanee C., Takabe T. 2015. Physio-biochemical and morphological characters of halophyte legume shrub, Acacia ampliceps seedlings in response to salt stress under greenhouse. Frontiers in Plant Science, 6:630.

Wani SP., Rockström J., Oweis TY. 2009. Rainfed agriculture: unlocking the potential, eds., (Vol. 7), Centre for Agriculture and Bioscience International. 